\title{
CDISC Protocol Entities Clinical Study Attribute Terminology
}

National Cancer Institute

\section{Source}

National Cancer Institute. CDISC Protocol Entities Clinical Study Attribute Terminology. NCI Thesaurus. Code C142191.

Terminology associated with the protocol entity clinical study attribute codelist of the Clinical Data Interchange Standards Consortium (CDISC). 